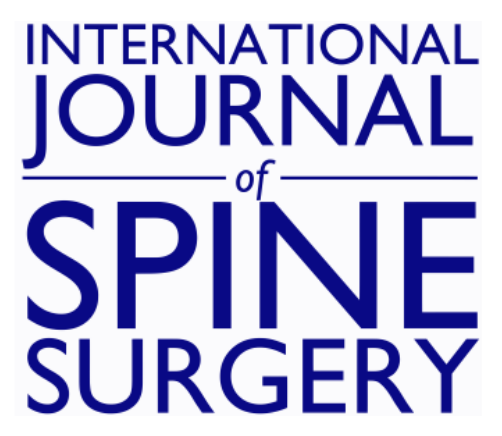

\title{
Preclinical Comparison of Thermal Tissue Effects from Traditional Electrosurgery and a Low-Temperature Electrosurgical Device during Anterior Cervical Discectomy and Fusion
}

KRIS RADCLIFF, PALANISWAMY VIJAY, RUBA F. SARRIS, MOLLY SPELTZ and JOSHUA G. VOSE

Int J Spine Surg 2018, 12 (4) 483-489

doi: https://doi.org/10.14444/5059

http://ijssurgery.com/content/12/4/483

This information is current as of April 26, 2023.

Email Alerts Receive free email-alerts when new articles cite this article. Sign up at: http://ijssurgery.com/alerts 


\title{
Preclinical Comparison of Thermal Tissue Effects from Traditional Electrosurgery and a Low-Temperature Electrosurgical Device during Anterior Cervical Discectomy and Fusion
}

\author{
KRIS RADCLIFF, MD, ${ }^{1}$ PALANISWAMY VIJAY, PhD, MPH ${ }^{2}$ RUBA F. SARRIS, MPH, ${ }^{2}$ MOLLY SPELTZ, \\ DVM ${ }^{3}$ JOSHUA G. VOSE, MD ${ }^{2}$ \\ ${ }^{1}$ Departments of Orthopedic Surgery and Neurological Surgery, Rothman Institute, Thomas Jefferson University, Philadelphia, Pennsylvania, ${ }^{2}$ Medtronic \\ Advanced Energy LLC, Portsmouth, New Hampshire, ${ }^{3}$ Medtronic Physiologic Research Laboratories, Coon Rapids, Minnesota
}

\begin{abstract}
Background: Exposure of the anterior cervical spine requires dissection in proximity to critical neurovascular structures. Monopolar electrosurgical (ES) devices generate heat in contacted tissues, resulting in thermal damage and temperature change. This study examined depth of thermal injury and temperature change associated with use of a lowtemperature electrosurgical device (LTD) compared to traditional electrosurgery during a cadaveric anterior cervical discectomy and fusion (ACDF) dissection.

Methods: ACDF was performed, using ES or LTD, on cervical spines (C3-4 and C4-5) from 2 fresh human cadavers with intact neck soft tissues and no history of surgery. Cadavers were maintained at $22-23^{\circ} \mathrm{C}$, and fiber-optic temperature sensors (Neoptix, Québec City, Québec, Canada) were placed near relevant structures to measure changes during dissection. Depth of thermal injury was assessed by hematoxylin and eosin and Masson's trichrome histology of fixed tissue specimens.

Results: Use of the LTD resulted in a statistically significant reduction in temperature change at platysma $(3.0 \pm$ 1.04 vs. $\left.11.41 \pm 3.10^{\circ} \mathrm{C}, P=.003\right)$, carotid sheath $\left(7.32 \pm 1.13\right.$ vs. $\left.15.57 \pm 2.56^{\circ} \mathrm{C}, P=.007\right)$, and longus colli $(6.11 \pm$ 1.32 vs. $\left.12.9 \pm 3.62^{\circ} \mathrm{C}, P=.016\right)$ compared to ES. Temperature change at the trachea was similar between groups (6.06 \pm 1.99 vs. $\left.4.96 \pm 1.89^{\circ} \mathrm{C}, P=.528\right)$. Histology showed that LTD produced less mean and maximal depth of thermal injury compared to ES (mean: 0.5 vs. $1.2 \mathrm{~mm}$; max: 0.9 vs. $1.8 \mathrm{~mm} ; P<.05$ ).

Conclusions: The results of this pilot study demonstrate that anterior cervical spine exposure using an LTD reduces tissue temperature change and depth of thermal injury compared to ES.

Clinical Relevance: Although exploratory, these results suggest that use of an LTD during ACDF may reduce the extent of thermal tissue injury during dissection. Future studies in live animal models are warranted to determine if thermal injury is a potential cause of common exposure-related complications, such as dysphagia and dysphonia.
\end{abstract}

Research Article

Keywords: anterior cervical discectomy and fusion, electrosurgery, spine surgery, temperature change, thermal injury

\section{INTRODUCTION}

Anterior cervical discectomy and fusion (ACDF) is an effective and well-established surgical procedure for the management of symptomatic degenerative cervical disk disease. Although ACDF generally leads to good clinical outcomes and an arthrodesis rate of $95 \%$ at 2 years, ${ }^{1}$ the rare complications associated with ACDF can be debilitating or life threatening. These complications can include laceration of the airway, nerves, vasculature, and other structures; cerebrospinal fluid leakage; laryngeal nerve palsy; persistent swallowing or speech disturbances; bladder and bowel problems; and paralysis. ${ }^{2-5}$ Such complications may be transient or permanent, depending on the severity of the injury.

Traditional electrosurgical (ES) devices are the mainstay of dissection and bleeding control during surgery, including ACDF. Despite their utility, the heat generated by these devices can cause unintended thermal injury to nearby critical structures and has been shown to impair wound healing, increase inflammation, depolarize nerves, injure vasculature, and lead to other adverse sequelae. ${ }^{4,6-8}$ Accordingly, novel ES devices have been developed that operate 


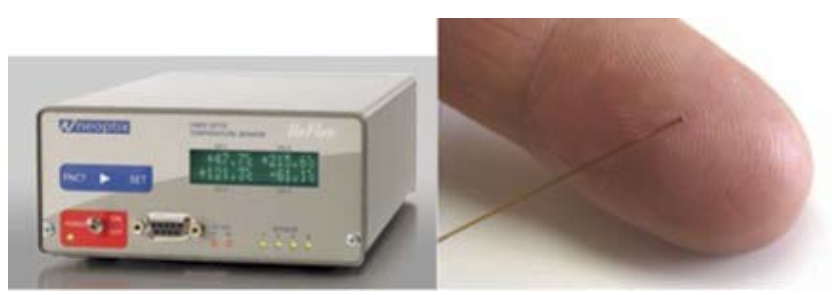

Figure 1. Fiber-optic system. The system consists of the measuring unit (left panel) and the fiber-optic temperature sensor (right panel). The bare fiber-optic temperature sensor is 300 microns in diameter (right panel).

at lower temperatures-between $40^{\circ} \mathrm{C}$ and $100^{\circ} \mathrm{C}$ compared to as high as $300^{\circ} \mathrm{C}$ for traditional ES devices. These lower temperatures can help to minimize thermal injury to critical structures during dissection and bleeding control with the ultimate goal of limiting the morbidity associated with electrosurgery.

To our knowledge, the evaluation of low-temperature ES devices (LTDs) for ACDF has not been reported in the literature. Thus, the purpose of the present study was to determine whether a representative LTD could reduce heat transfer and depth of thermal injury in adjacent tissues during the ACDF procedure when compared to a traditional ES device. To this end, we used a cadaveric model to measure in situ temperature changes near critical anatomical structures that may be at risk during routine ACDF dissection. The depth of thermal injury was assessed quantitatively by histological analysis of harvested tissues.

\section{MATERIALS AND METHODS}

\section{ES Devices}

The LTD used for this study was the PEAK Surgery System (Medtronic Advanced Energy, Portsmouth, NH), which consists of the microcontroller-based, isolated output, PULSAR Generator and single-use PEAK PlasmaBlade tissue dissection devices. The representative ES device used in this study was the Valleylab ES pencil, button switch, and disposable (uncoated) metal blade electrode (Model E2450H) powered by the Valleylab Force FX generator (Medtronic Inc., Minneapolis, MN).

\section{Human Cadaver Spines}

Two human cadaveric cervical spines (C1-T3) with intact adjacent soft tissues of the neck were obtained from approved vendors (Anatomy Bequest Program, University of Minnesota, Minneapolis,
MN). Both cadaveric spines had no history of muscular disease or prior surgery and were less than 120 hours postmortem. On the day of surgery, the cadaveric spines were acclimated to and maintained at room temperature $\left(22-23^{\circ} \mathrm{C}\right)$ and prepped in the usual fashion.

\section{Temperature Sensor Placement}

The standard for making accurate temperature measurements in an electrically noisy environment (as occurs with ES devices) is a fiber-optic temperature sensor. These devices exploit the property of crystalline materials, which have an optical reflectance that changes with temperature. An excited pulse of light of specific intensity is sent down the fiber-optic cable, and the intensity of the reflected signal is measured by the device so that the temperature can be determined. These sensors can provide real-time, continuous temperature measurements with no radio frequency interference and are therefore considered the standard for temperature measurement of energy-based systems. Fiber-optic sensors of various sizes (as small as $<0.5 \mathrm{~mm}$ in diameter) are available and have been used in medical research studying ablation and surgical procedures. ${ }^{9,10}$ The Neoptix Reflex system (Neoptix, Québec City, Québec, Canada; Figure 1) was selected for use in the present study for its ability to provide real-time, reproducible measurements and for the availability of small probe sizes.

Prior to each ACDF dissection procedure, the calibrated fiber-optic sensors were placed and secured at or close to critical structures (as close as $8-10 \mathrm{~mm}$ ) during the ACDF dissection procedure. Placement was verified by fluoroscopy before continuing the ACDF dissection. Temperature at the sensors was measured continuously in real time as the procedure was performed.

\section{ACDF Procedure}

The ACDF procedures were performed on the cadaveric cervical spines (C3-4 and C4-5) under non-good laboratory practices conditions at Physiological Research Laboratories (Minneapolis, $\mathrm{MN}$ ). Each cadaveric spine was dissected with both the LTD (set at Cut 6 mode, $20 \mathrm{~W}$ ) and the ES (set on Cut mode, $25 \mathrm{~W}$ ); the two devices were used on different sides of the spine, chosen at random.

The procedure was carried out as previously described. ${ }^{11}$ Briefly, a skin incision was performed transversely to the level of platysma. The plane 
between the carotid sheath (laterally) and the esophagus and trachea (medially) was dissected and the omohyoid divided as necessary. The prevertebral tissues and any visible longus colli muscles overlying the anterior longitudinal ligaments and vertebral bodies were dissected, and an incision of the anterior annulus was performed. A vertical traction was placed on the vertebral bodies, and the cut annulus was removed, along with the anterior two-thirds of the disc. The osseous lips present on the superior and inferior vertebral bodies were drilled, and the disc was removed. The procedure was repeated on the contralateral side with the comparative ES device.

\section{Histopathologic Determination of Thermal Injury in Excised Tissues}

Sections of platysma, carotid sheath, and longus colli were excised with scalpel after completion of the $\mathrm{ACDF}$ and temperature measurement phase, fixed in $10 \%$ normal saline-buffered formalin, and stained with hematoxylin and eosin (H\&E) and Masson's trichrome. H\&E stain was used for assessing basic tissue structure and inflammation: muscle and other tissues damaged by thermal application appear as bright pink with a hyalinized appearance compared to normal tissues that appear as lighter or darker pink. Masson's trichrome stain was used for identifying collagen, both new and old, along with muscle damage. Damaged muscle appears purple compared to normal muscle, which stains red. Tissue blocks ( $2 \mathrm{~cm}$ long by $4 \mathrm{~mm}$ thick) were trimmed, and the depth of thermal injury, defined as the width of the collagen and muscle damage perpendicular from the cut surface and into the tissue, was measured. Measurements were taken at 3 representative locations at each critical anatomical location for the 2 spines and recorded as the maximum depth of injury, the minimum depth of injury, and a middle depth of injury in millimeters. The mean depth of thermal injury was the average of the 3 measurements.

\section{STATISTICAL METHODS}

\section{Sample Size}

This was a pilot study comparing the temperature changes and thermal injury caused by LTD and ES during ACDF; therefore, no formal sample size calculation was performed. Two cadaver spines
Table 1. Placement of temperature sensors in critical structures.

\begin{tabular}{lc}
\hline Location & $\begin{array}{c}\text { Sensor Placed? } \\
\text { (Yes/No) }\end{array}$ \\
\hline Platysma & Yes \\
Esophagus & Yes \\
Carotid sheath & Yes \\
Longus colli & Yes \\
Left and right transverse foramen close to spinal cord & No \\
Vertebral artery & No \\
Superior laryngeal nerve & No \\
Recurrent laryngeal nerve & No \\
Spinal canal & Yes \\
Trachea & Yes \\
\hline
\end{tabular}

were dissected, both with LTD and ES (1 side each), yielding an $N$ of 2 for each device.

Temperature Change Measurements and Analysis

Temperature change (mean $\pm \mathrm{SD}$ ) was calculated from 3-4 peak temperatures recorded from each device in each location in both spines while the devices were in use. $P$ values comparing LTD and ES were calculated using an $F$ test, then by a 2 -sided $t$ test for equal or unequal variance with a 2-tailed distribution. Confidence intervals at $95 \%$ were plotted as error bars for all data. $P$ values $<.05$ were considered statistically significant.

\section{Thermal Damage}

Maximum, minimum, and middle depth of thermal damage measurements (in $\mathrm{mm}$ ) were taken at three representative locations of each anatomical location in both spines. The mean was the average of the 3 measurements. $P$ values were calculated using an unpaired Student $t$ test with a prespecified alpha of $<0.05$.

\section{RESULTS}

\section{Cadaveric Spines and Probe Placement}

The 2 cadaveric spines used in this study were 78 and 108 hours postmortem. Attempts to place calibrated fiber-optic temperature sensors were successful in all but 4 critical structures (the left and right transverse foramen close to the spinal cord, the vertebral artery, the superior laryngeal nerve, and the recurrent laryngeal nerve). The placement of sensors is provided in Table 1.

\section{Temperature Changes in Dissected Tissues}

The LTD generated a statistically significant reduction in temperature elevation at the platysma 
Table 2. Temperature changes in critical structures.

\begin{tabular}{|c|c|c|c|c|c|}
\hline Location & $\begin{array}{c}\text { LTD Temperature Change } \\
\text { Mean } \pm \mathrm{SD}\left({ }^{\circ} \mathrm{C}\right)\end{array}$ & $\begin{array}{l}\text { ES Temperature Change } \\
\text { Mean } \pm \mathrm{SD}\left({ }^{\circ} \mathrm{C}\right)\end{array}$ & $\begin{array}{c}\text { LTD } \\
\% \text { Reduction }\end{array}$ & $\begin{array}{l}\text { 95\% Confidence } \\
\text { Interval }\end{array}$ & $\begin{array}{l}P \text { Value } \\
(t \text { Test })\end{array}$ \\
\hline Platysma & $3.0 \pm 1.04$ & $11.41 \pm 3.10$ & 74 & $4.24-12.57$ & .003 \\
\hline Carotid sheath & $7.32 \pm 1.13$ & $15.57 \pm 2.56$ & 53 & $3.77-12.73$ & .007 \\
\hline Longus colli & $6.11 \pm 1.32$ & $12.9 \pm 3.62$ & 53 & $1.87-11.7$ & .016 \\
\hline Trachea & $6.06 \pm 1.99$ & $4.96 \pm 1.89$ & 12 & $-5.49-3.30$ & .528 \\
\hline Esophagus & $\begin{array}{l}\text { Not enough data to } \\
\text { perform analysis }\end{array}$ & & & & \\
\hline
\end{tabular}

Abbreviation: LTD, low-temperature electrosurgical device.

$\left(3.0 \pm 1.04\right.$ vs. $\left.11.41 \pm 3.10^{\circ} \mathrm{C}, P=.003\right)$, carotid sheath $\left(7.32 \pm 1.13\right.$ vs. $\left.15.57 \pm 2.56^{\circ} \mathrm{C}, P=.007\right)$, and longus colli $\left(6.11 \pm 1.32\right.$ vs. $12.9 \pm 3.62^{\circ} \mathrm{C}, P=$ .016) compared to ES. Temperature in the trachea, however, was not different in the two groups (6.06 \pm 1.99 vs. $4.96 \pm 1.89^{\circ} \mathrm{C}, P=.528$; Table 2$)$. No change in temperature was observed in the spinal canal. Data for the esophagus were insufficient for analysis.

\section{Histologic Assessment of Thermal Injury}

Histological assessment by H\&E and Masson's trichrome staining for depth of thermal injury showed that the LTD produced statistically significantly lower mean and maximum depth of injury in all tissues excised (mean: $0.5 \pm 0.2$ vs. $1.2 \pm 0.4$ mm; max: 0.9 vs. $1.8, P<.05)$ compared to ES. A reduction in maximum depth of thermal tissue injury was also observed in the platysma with the LTD compared to the ES (Table 3), but no statistical analysis could be conducted because only 1 ES tissue section was examined. Representative histopathologic sections of the different tissues are presented in Figures 2 and 3.

\section{DISCUSSION}

Damage to blood vessels and nerves from the use of ES devices has been identified as the cause for many serious complications. Depending on the proximity to the adjacent critical structures and severity of injury, damage to those structures can result in transient or permanent injury. ${ }^{12,13}$

Table 3. Depth of thermal injury.

\begin{tabular}{lcclcc}
\hline & \multicolumn{2}{c}{ Mean Depth $(\mathbf{m m})$} & & \multicolumn{2}{c}{ Maximum Depth $(\mathbf{m m})$} \\
\cline { 2 - 3 } \cline { 6 - 6 } Tissue & LTD & ES & & LTD & ES \\
\hline Carotid artery & 1.2 & 1.6 & & 0.6 & 0.9 \\
Longus colli $^{\text {Platysma }}{ }^{1}$ & 1.1 & 2.0 & & 0.4 & 0.8 \\
& 0.3 & 0.3 & & 0.7 & 1.5 \\
\hline
\end{tabular}

Abbreviations: LTD, low-temperature electrosurgical device; ES. electrosurgery. ${ }^{1}$ ES vs. LTD comparison is not reliable due to sample size $(n=1)$.
Several devices have been designed to operate at lower temperature in order to minimize thermal injury to dissected tissues. The LTD used in this study has previously been shown to significantly decrease the depth of thermal injury during dissection of skin and fascia in clinical and preclinical studies, minimizing collateral tissue damage, and providing a healing profile equivalent to scalpel. ${ }^{14-19}$ This LTD has also been shown to reduce scarring and wound necrosis ${ }^{20}$ as well as to improve surgery time, hospital stay, and cost in select applications. ${ }^{21}$

This LTD has not yet been assessed in ACDF; thus, this pilot study was designed to evaluate and compare its properties with ES in a cadaveric model. First, we developed a method to measure changes in temperature within critical structures adjacent to the dissection using sensitive fiber-optic sensors. Using this method, we showed that the LTD resulted in at least $50 \%$ less temperature change in the platysma, carotid sheath, and longus colli, which are adjacent structures that could potentially be affected by dissection during an ACDF. Consistent with these measurements, histological assessment of these tissues showed a reduced depth of thermal injury with the use of the LTD. These results are in agreement with those obtained by Naruns et $\mathrm{al}^{16}$ and Ruidiaz et $\mathrm{al}^{18}$ in breast cancer surgery, in which the authors had shown reduced thermal injury to the margin of excised tumor tissue following lumpectomy.

The present study has a number of important limitations. The sample size was small, consisting of only 2 spines. Although the cadaveric spines were maintained at room temperature, results obtained in unperfused tissues may not be fully relevant to results obtained in a live individual; for example, hemostasis was unnecessary in these specimens. In live patients, when the superior thyroid artery at C34 or inferior thyroid artery at C6-7 must be sacrificed, the dissection requires ES hemostasis. While this function may cause thermal injury on its 
Electrosurgery

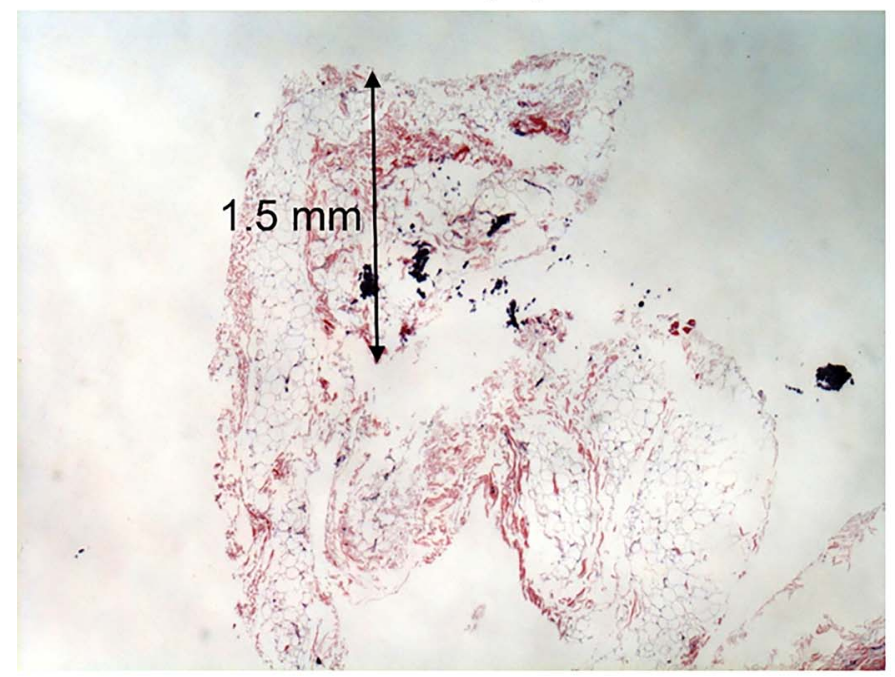

LTD

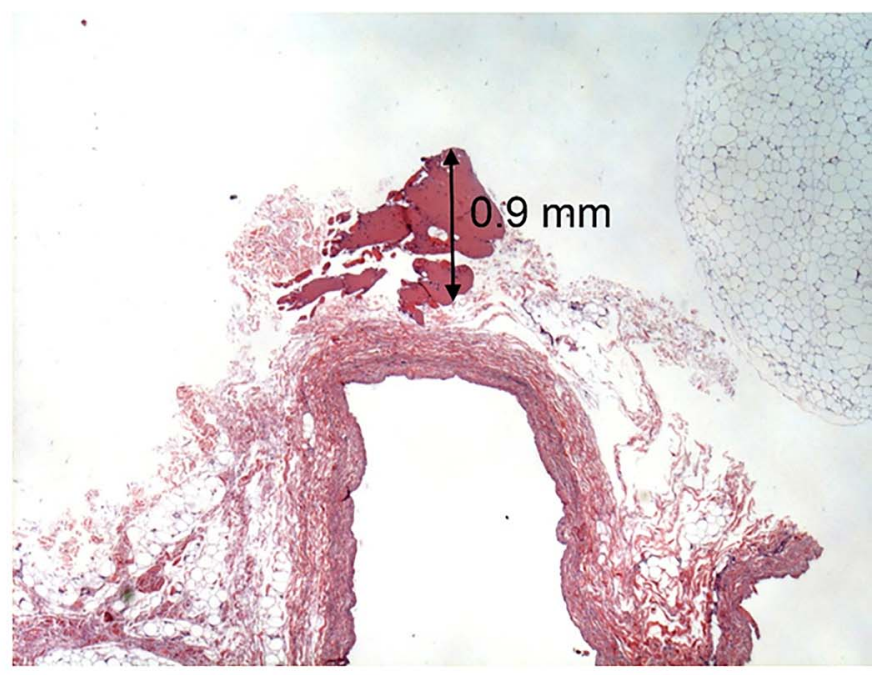

b

\section{Longus Colli}

Electrosurgery

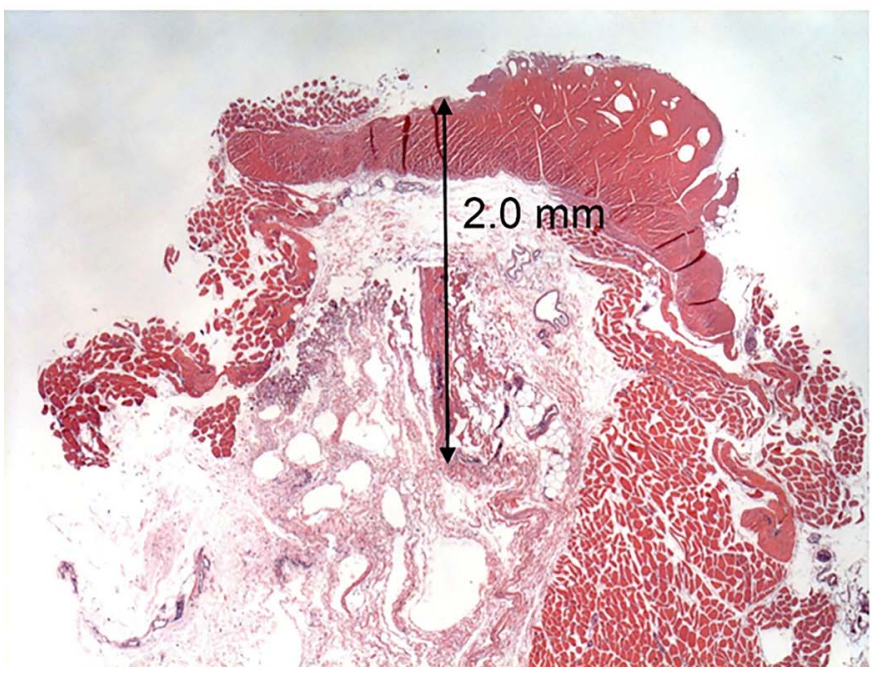

LTD

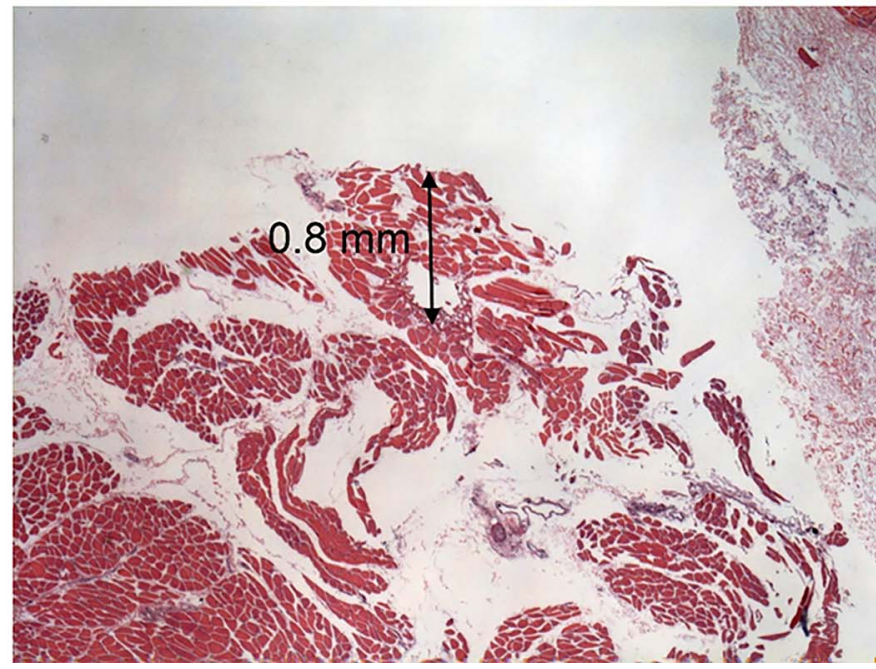

Figure 2. H\&E staining showing depth of thermal injury in the carotid artery and longus colli. Mature adipose, connective, and collagen tissues are stained dark pink, indicating thermal injury to the tissue, while lighter pink indicates no evidence of thermal injury. Upper panel: carotid artery. Lower panel: longus colli. Magnified 20X.

own, in our experimental design, its potential effects could not be assessed. However, using human cadavers is the only way to determine histological thermal damage in ACDF because in living patients, no tissue is excised during this procedure except for a small portion of the disc. This is in contrast to tumor resection or abdominoplasty, in which tissues are excised and are therefore readily available for histopathological analysis of thermal damage.

Another limitation of the study was our inability to place temperature sensors at or near 4 critical structures: the left and right transverse foramen close to the spinal cord, the vertebral artery, the superior laryngeal nerve, and the recurrent laryngeal nerve. In cadavers, certain structures, such as nerves, are difficult to locate and successfully place and fix the sensors. Thus, in order to validate and extend the present results in cadavers, temperature measurements in critical structures should be performed during ACDF surgery in live patients. However, to our knowledge, the use of temperature sensors to measure temperature changes has never been evaluated in patients undergoing ACDF. The only study reporting in situ measurements of 


\section{Longus Colli}
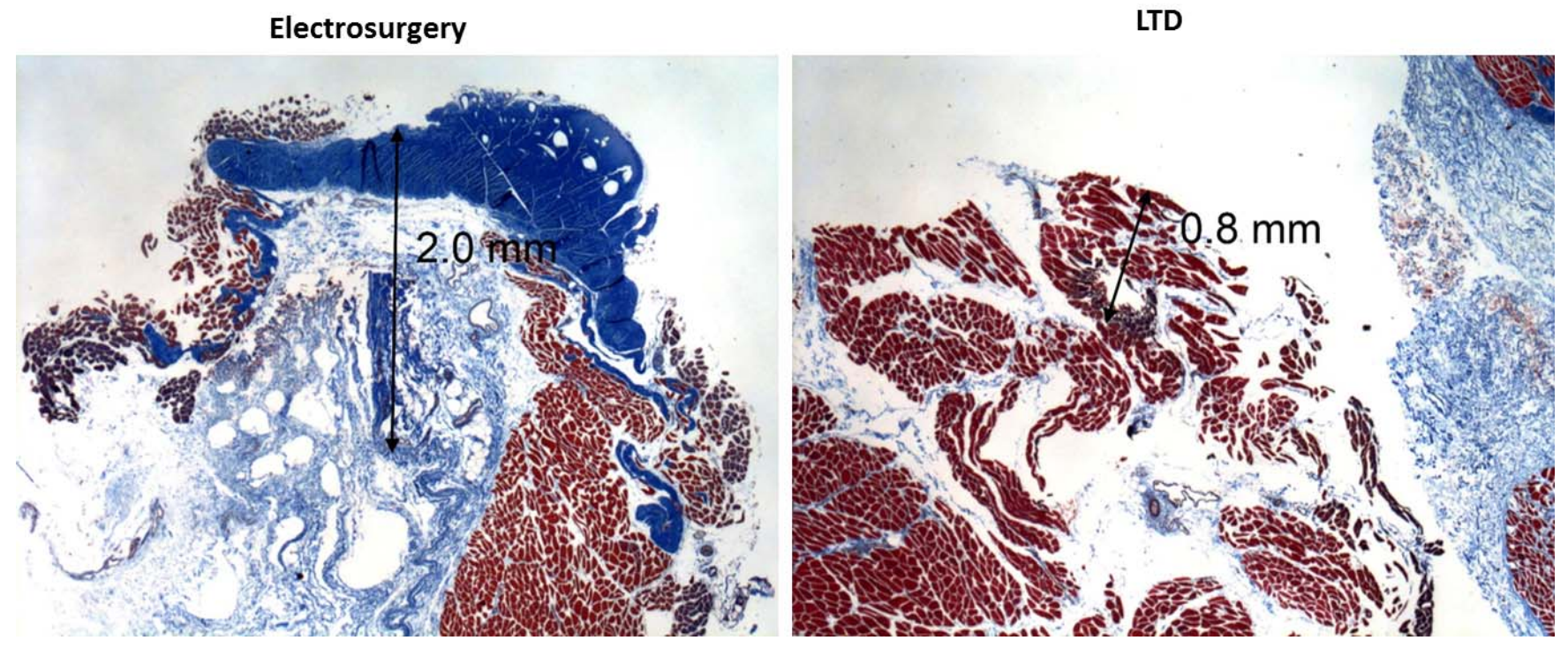

Figure 3. Masson's trichrome staining showing depth of thermal injury in the carotid artery and longus colli. Adipose and connective tissue is stained darker blue, indicating thermal injury, while the adjacent lighter blue indicates no evidence of thermal injury. The damaged collagen is the darkest blue collagen at the top of the image. Upper panel: carotid artery. Lower panel: longus colli. Magnified 20x.

temperature changes using temperature sensors in live human patients was performed in open hysterectomy. ${ }^{10}$

Histological analysis of the tissues was not performed in a blinded manner, which could have biased the measurements of the depth of thermal injury, and, finally, correlation of thermal injury to clinical complications was not possible in this study. However, it is possible that the differences in thermal injury in this study may correspond to clinically relevant nerve injury or dysphagia; these represent areas for further study.

In conclusion, the results of this small, comparative temperature and histological pilot assessment suggest a potential benefit for using LTDs during ACDF because they produce less change in temperature and minimize thermal injury in dissected tissues compared with traditional ES devices. Further studies comparing LTDs to ES in living animals and in human patients undergoing ACDF should be performed to confirm these findings. Since histopathological analysis of live tissue in the dissection plane is not possible, the end points measured in these studies should include (1) temperature changes in situ during surgery (using fiber-optic temperature sensors); (2) outcomes including time to healing, scarring, and tissue necrosis; and (3) incidence of postoperative complications, such as dysphagia or dysphonia.

\section{ACKNOWLEDGMENTS}

The authors thank Kent Wika (Medtronic) for assistance with surgical procedures, Matthew Hoffman (Medtronic) for assistance with temperature measurements, and Jeanne McAdara, PhD, and Florence Paillard, $\mathrm{PhD}$, for medical writing assistance. The authors wish to thank the individuals who donated their bodies for the advancement of education and research.

\section{REFERENCES}

1. Upadhyaya CD, Wu JC, Trost G, et al. Analysis of the three United States Food and Drug Administration investigational device exemption cervical arthroplasty trials. J Neurosurg Spine. 2012;16(3):216-228.

2. Fountas KN, Kapsalaki EZ, Nikolakakos LG, et al. Anterior cervical discectomy and fusion associated complications. Spine (Phila Pa 1976). 2007;32(21):2310-2317.

3. Monfared A, Kim D, Jaikumar S, Gorti G, Kam A. Microsurgical anatomy of the superior and recurrent laryngeal nerves. Neurosurgery. 2001;49(4):925-932; discussion 932.

4. Nanda A, Sharma M, Sonig A, Ambekar S, Bollam P. Surgical complications of anterior cervical diskectomy and fusion for cervical degenerative disk disease: a single surgeon's experience of 1,576 patients. World Neurosurg. 2014;82(6):1380-1387.

5. Peng CW, Chou BT, Bendo JA, Spivak JM. Vertebral artery injury in cervical spine surgery: anatomical considerations, management, and preventive measures. Spine J. 2009;9(1):70-76. 
6. Jacobson MT. Pulsed electron avalanche knife PlasmaBlade. Exp Rev Obstet Gynecol. 2010;5(1):19-22.

7. Massarweh NN, Cosgriff N, Slakey DP. Electrosurgery: history, principles, and current and future uses. J Am Coll Surg. 2006;202(3):520-530.

8. Keenan KM, Rodeheaver GT, Kenney JG, Edlich RF. Surgical cautery revisited. Am J Surg. 1984;147(6):818-821.

9. Ko R, Tan AH, Chew BH, Rowe PE, Razvi H. Comparison of the thermal and histopathological effects of bipolar and monopolar electrosurgical resection of the prostate in a canine model. BJU Int. 2010;105(9):1314-1317.

10. Wallwiener CW, Rajab TK, Krämer B, Isaacson KB, Brucker S, Wallwiener M. Quantifying electrosurgery-induced thermal effects and damage to human tissue: an exploratory study with the fallopian tube as a novel in-vivo in-situ model. $J$ Minim Invasive Gynecol. 2010;17(1):70-77.

11. Hoppenfeld S, deBoer P, Buckley R. Surgical Exposures in Orthopaedics: The Anatomic Approach. 4th ed. Philadelphia, PA: Lippincott Williams \& Wilkins; 2009.

12. Chen RK, Than KD, Wang AC, Park P, Shih AJ. Comparison of thermal coagulation profiles for bipolar forceps with different cooling mechanisms in a porcine model of spinal surgery. Surg Neurol Int. 2013;4:113.

13. Elliott-Lewis EW, Jolette J, Ramos J, Benzel EC. Thermal damage assessment of novel bipolar forceps in a sheep model of spinal surgery. Neurosurgery. 2010;67(1):166-171; discussion 171.

14. Chang EI, Carlson GA, Vose JG, Huang EJ, Yang GP. Comparative healing of rat fascia following incision with three surgical instruments. J Surg Res. 2011;167(1):e47-e54.

15. MacDonald JD, Bowers CA, Chin SS, Burns G. Comparison of the effects of surgical dissection devices on the rabbit liver. Surg Today. 2014;44(6):1116-1122.

16. Ruidiaz ME, Cortes-Mateos MJ, Sandoval S, et al. Quantitative comparison of surgical margin histology following excision with traditional electrosurgery and a low-thermalinjury dissection device. J Surg Oncol. 2011;104(7):746-754.

17. Ruidiaz ME, Messmer D, Atmodjo DY, et al. Comparative healing of human cutaneous surgical incisions created by the PEAK PlasmaBlade, conventional electrosur- gery, and a standard scalpel. Plast Reconstr Surg. 2011;128(1):104-111.

18. Naruns PL, Vose JG, Atmodjo DY, Sangoi AR. A randomized controlled trial of the PEAK PlasmaBlade in open breast biopsy compared to scalpel and traditional electrosurgery. Paper presented at: American Society of Breast Surgeons 11th Annual Meeting; 2010; Las Vegas, NV.

19. Loh SA, Carlson GA, Chang EI, Huang E, Palanker D, Gurtner GC. Comparative healing of surgical incisions created by the PEAK PlasmaBlade, conventional electrosurgery, and a scalpel. Plast Reconstr Surg. 2009;124(6):1849-1859.

20. Fine RE, Vose JG. Traditional electrosurgery and a low thermal injury dissection device yield different outcomes following bilateral skin-sparing mastectomy: a case report. $J$ Med Case Reports. 2011;5(1):212.

21. Kypta A, Blessberger H, Saleh K, et al. An electrical plasma surgery tool for device replacement-retrospective evaluation of complications and economic evaluation of costs and resource use. Pacing Clin Electrophysiol. 2015;38(1):28-34.

Disclosures and COI: K. Radcliff is a paid consultant of Medtronic but was not compensated for this study; P. Vijay, R. Sarris, M. Speltz, and J. Vose are employees of Medtronic.

Corresponding Author: Kris Radcliff, MD, Orthopedic Surgery and Neurological Surgery, Rothman Institute, Thomas Jefferson University; Philadelphia, PA 19107. Phone: (609) 573-3301; Fax: (609) 407-6445; Email: kris.radcliff@ rothmaninstitute.com.

Published 31 August 2018

This manuscript is generously published free of charge by ISASS, the International Society for the Advancement of Spine Surgery. Copyright (C) 2018 ISASS. To see more or order reprints or permissions, see http://ijssurgery.com. 